\title{
Pure Cognitivism and Beyond
}

\section{Attila Tanyi}

\section{Acta Analytica}

International Periodical for Philosophy in the Analytical Tradition

ISSN 0353-5150

Volume 29

Number 3

Acta Anal (2014) 29:331-348

DOI 10.1007/s12136-013-0210-8

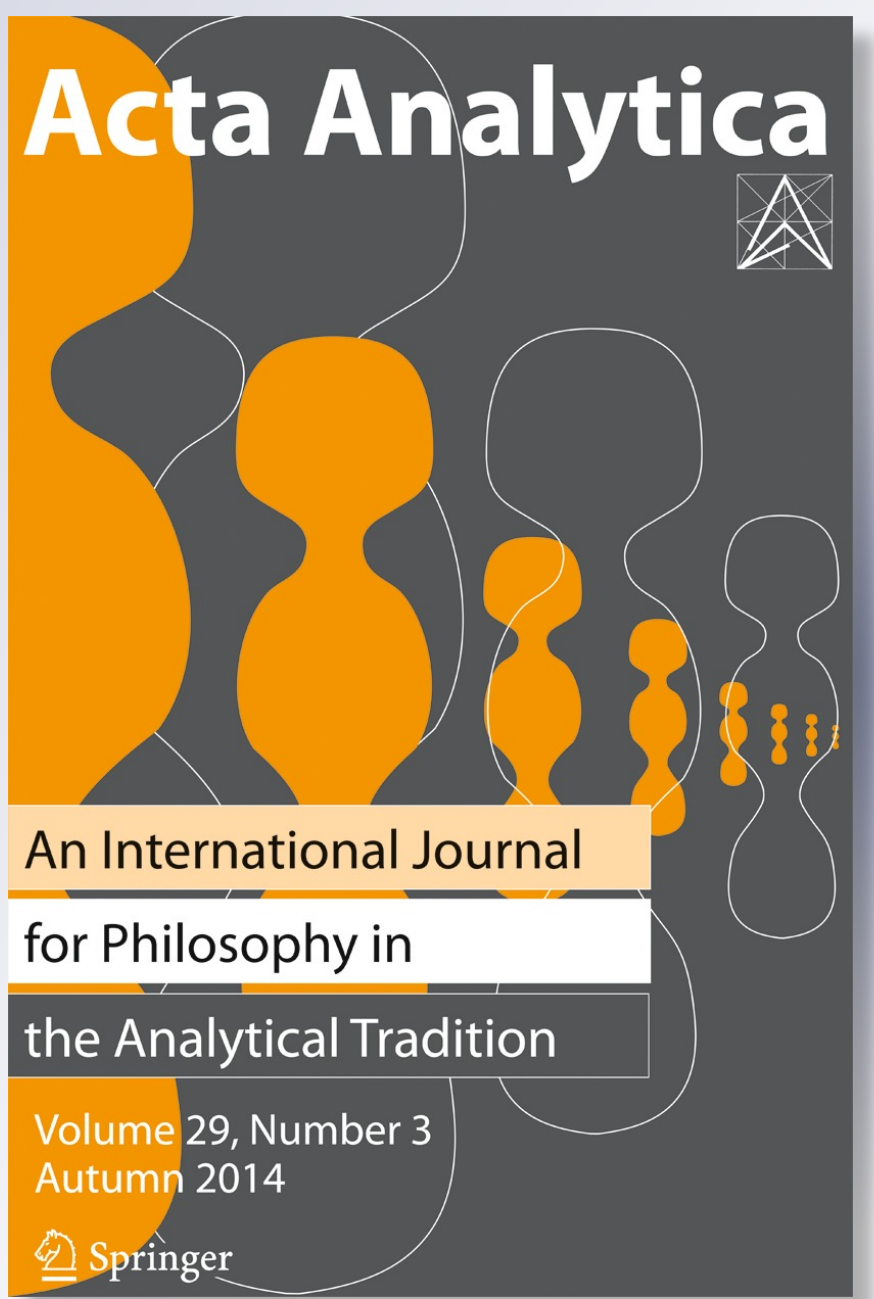

Springer 
Your article is protected by copyright and all rights are held exclusively by Springer Science +Business Media Dordrecht. This e-offprint is for personal use only and shall not be selfarchived in electronic repositories. If you wish to self-archive your article, please use the accepted manuscript version for posting on your own website. You may further deposit the accepted manuscript version in any repository, provided it is only made publicly available 12 months after official publication or later and provided acknowledgement is given to the original source of publication and a link is inserted to the published article on Springer's website. The link must be accompanied by the following text: "The final publication is available at link.springer.com". 


\title{
Pure Cognitivism and Beyond
}

\author{
Attila Tanyi
}

Received: 20 February 2013 / Accepted: 10 September 2013 / Published online: 24 October 2013

(C) Springer Science+Business Media Dordrecht 2013

\begin{abstract}
The article begins with Jonathan Dancy's attempt to refute the Humean Theory of Motivation. It first spells out Dancy's argument for his alternative position, the view he labels 'Pure Cognitivism', according to which what motivate are always beliefs, never desires. The article next argues that Dancy's argument for his position is flawed. On the one hand, it is not true that desire always comes with motivation in the agent; on the other, even if this was the case, it would still not follow that desire is identical with the state of being motivated. When this negative work is done, the article turns to some positive, albeit admittedly tentative remarks about what sort of cognitivist theory of motivation one should endorse. The aim at this point is not to present a brand new theory, but rather to sketch an alternative that stems from what Dancy himself says and is in line with many of his endorsed commitments in other areas. In this way, by moving beyond Pure Cognitivism, the paper sketches a different, but still 'Dancyesque' theory of motivation.
\end{abstract}

Keywords Motivation · Pure cognitivism · Desire · Jonathan Dancy · Perception · Emotions

\section{Against the Humean Theory of Motivation: Dancy's Pure Cognitivism}

The problem of motivation has always been among the favorite topics of philosophers. This is understandable: we want to know why we do the things we do. Moreover, we also want to know what counts as (intentional) action, and motivation, it is natural to suppose, is intimately related to action. And if some kind of motivational internalism is true, that is, if there is an intimate connection between ethical statements or truths and

\footnotetext{
A. Tanyi

Department of Philosophy, University of Liverpool, Liverpool, UK

\section{A. Tanyi $(\bowtie)$}

Zukunftskolleg \& Department of Philosophy, University of Konstanz, Universitätsstraße 10, 78464 Konstanz, Germany

e-mail: attila.tanyi@uni-konstanz.de

URL: www.uni-konstanz.de/zukunftskolleg
} 
motivation, then our views about motivation will determine, or at least influence, the sort of meta-ethical theory we endorse. Of course, these connections must be worked out in detail, and this can prove to be - as often in philosophy — an arduous exercise. Still, details and difficulties notwithstanding, these points well indicate how important the question of motivation is for philosophy. ${ }^{1}$

The Humean Theory of Motivation (HTM) is probably the most influential account of our motivating reasons: of what moves us - humans, perhaps, animals - to act. There exist many versions of HTM, and it would take another paper to sort out the differences. In this article I define HTM by three criteria, which set requirements that a theory of motivation must meet in order to qualify as Humean. ${ }^{2}$ The three criteria - the Motivational Criterion (MC), the Existence Criterion (EC), and the Independence Criterion (IC) - claim the following:

(MC) The agent's motivating reason is constituted by a pair of desire and meansend belief: the desire provides the 'push' that the belief 'channels' to the action. ${ }^{3}$ (EC) The two mental states, the desire and the means-end belief, which constitute the agent's motivating reason, are real existences.

(IC) The two mental states, the desire and the means-end belief, which constitute the agent's motivating reason, are distinct existences: it is (at least) logically possible that they come apart.

Although it is MC that is typically cited as defining HTM, the other two theses are equally important. It is possible to meet $\mathrm{MC}$ while holding that the desire involved is a mere logical ghost, which we ascribe to the agent just in virtue of being motivated (Nagel 1970; Bond 1983; Schueler 1995). Hence the need for EC. And even if the agent's motivating reason involves a desire as a real existence, it could still happen that as a mental state desire cannot be pried apart from because it is identical with or is entailed by — a belief with which it together comprises the agent's motivating reason (McDowell 1978, 1979). Hence the need for IC.

There have been many attempts to refute HTM. This article takes issue with one anti-Humean proposal. Jonathan Dancy $(1993,2000)$ has repeatedly argued that there is an alternative to HTM, a cognitivist theory of motivation that is superior to other cognitivist theories of motivation in several respects. ${ }^{4}$ Dancy calls the theory Pure Cognitivism (PC), because it claims that the agent's motivating reason is composed solely of beliefs. PC accepts EC and IC, but rejects MC (Dancy 2000: 90).

\footnotetext{
${ }^{1}$ For the first connection, between action and motivation, see Davidson (1963), Mele (2003), Chap. 3, Smith (2003: 460-3), Dancy (2003: 483-4); for the second connection, between ethics and motivation, see Darwall (1992), Dancy (2000: 16-9, 151-3), and Smith (2001: 98-101).

${ }^{2}$ Cf. Smith (2010). Sometimes a fourth criterion is cited among the defining theses of HTM; see Cuneo (2002). Roughly, it is the claim that the desire that motivates one to act is not causally generated solely by cognitive states. However, many Humeans do not endorse this view (Smith 1994: 179-181, 213-4; Hubin 1996: 43; Shaver 2006: 5-6), and Dancy (2000: 79) also argues against it.

${ }^{3}$ This is deliberately metaphorical since it is an unresolved debate how one cashes out the different roles desire and belief play in motivation on HTM.

${ }^{4}$ Dancy's main cognitivist targets are pure ascriptivism (Nagel 1970: 29-30), motivated desires (Nagel 1970: 29), and besires (McDowell 1978, 1979; McNaughton 1988: Chap. 7; Phillips 1977). In addition, Dancy (1993: 29-30; 2000: 91) claims that PC tackles Michael Smith's (1994: Chap. 4) master argument in favor of HTM.
} 
Granting the truth of the claim that PC is the best cognitivist theory of motivation available, it is even more surprising that $\mathrm{PC}$ has not received much attention in the literature. ${ }^{5}$ This might be because Dancy's own attitude toward psychologistic accounts of motivation, i.e., views that take motivating reasons to be mental states, is negative. His 'real' theory of motivation is non-psychologistic, and PC is intended only as a prelude to it, albeit an important one. ${ }^{6}$ My inquiry will, however, be confined to asking if motivating reasons are mental states, what those mental states are; doing more lies beyond the scope of the present article. I will, moreover, keep Dancy as the addressee of my discussion, although at several points I will go beyond his existing views. Since PC is a theory that originates from Dancy, it is natural, and also simplifies discussion, to address him as the subject of my investigation.

After these preliminaries, let us turn to Dancy's argument for PC. From what Dancy (2000: 85-7) says, we can reconstruct the following line of thought:

(1) The agent's motivating reason is what explains the agent's action.

(2) What explains the agent's action is what motivates that action.

(3) What motivates the agent's action ('motivator') is different from the agent's state of being motivated ('motivatedness').

(4) This is because the explanation of motivatedness is structurally similar to the explanation of action: it is what needs to be explained, not what explains.

Therefore,

(5) The agent's motivating reason is identical with the motivator, not with the motivatedness (from 1-4).

(6) There is no desire without corresponding motivation in the agent.

Therefore,

(7) To desire is to be motivated: desire is the motivatedness (from 6).

Therefore,

(8) What motivates must be something else than desire (from 3).

(9) This 'something else' must be a belief.

Therefore,

(10) What motivates is always a belief, never a desire (from 8 and 9).

Therefore,

(11) The agent's motivating reason is composed solely of beliefs (from 5 and 10).

Several claims in this argument can be questioned. I will focus on two. In the next section (2), I will refute premise (6) as well as reject the inference to sub-conclusion (7). After this, in Sect. 3, I will offer some tentative remarks on

\footnotetext{
${ }^{5}$ The only sustained treatment is in Lohmar (2008). However, his focus is different from mine.

${ }^{6}$ Here is Dancy (2000: 77): 'We need to understand that the cognitive lies at the basis of motivation if we are to get into a position from which we can see that what motivates us is not a state of ourselves at all, but rather the nature of the situation.' See also Dancy $(2003,2005,2006)$ for similar statements.
} 
how a cognitivist theory of motivation could be built on the metaphysics and epistemology that Dancy, at least in part, endorses. Although PC is a failure, there is - cognitivist and 'Dancyesque' - life beyond it, or so I will argue. The article then ends with a brief summary and some concluding remarks (Sect. 4).

\section{Desire and Motivation}

Since establishing the truth or falsity of premise (6) requires lengthy treatment, it helps if we first deal with sub-conclusion (7). This claim, as noted above, makes an inference: since there is no desire without corresponding motivation in the agent, to desire is to be motivated: desire is the motivatedness, as Dancy puts it. However, this inference is false. Here is why.

We must distinguish three questions: (i) what motivatedness consists in; (ii) what entails motivatedness; (iii) what explains motivatedness. Dancy intends subconclusion (7) to make a claim about question (i), but the idea that desire always comes with corresponding motivation in the agent does not take us beyond question (ii). That is, were it to turn out that there can be no desire without corresponding motivation in the agent, this does not take us farther than the claim that desire entails motivation. However, this is not enough for Dancy, since entailment is not identity, and if there is no identity between motivatedness and desire, the inference to subconclusion (7) collapses. In fact, going one step further, one could just claim that it is exactly because that desire entails motivatedness that it is the motivator, being separate from that which it entails (thus explains), namely the motivatedness. To this Dancy cannot reply that it is a conceptual truth that to desire $i$ s to be motivated, since this would beg the question. For the issue is what Dancy provides in support of this claim and the problem is that what he provides — that there can be no desiring without corresponding motivation - does not take us anywhere near to a conceptual identity thesis. Hence the false inference and the collapse of Dancy's argument for sub-conclusion (7).

But let us rest this problem for the moment. For the claim in premise (6) on which sub-conclusion (7) is based, that desire always comes with a corresponding motivation in the agent, is also far from obviously true. In particular, there seem to be desires that do not involve the agent's being motivated to do, have or pursue what her desire is about. In what follows I will present and discuss one such example, an instance of what, in a different context, Daniel Friedrich calls 'non-actable desires.,

His example is of Harry who fancies Paula and wants her to fancy him too. However, he rejects his friend's advice to do things to make her fall in love with him - buy her flowers and new clothes, be attentive to what she says, etc. — because he abhors the thought of doing anything that would mold her affections towards him. Acting in such ways, Harry thinks, would be against the ideal of romantic love and is

\footnotetext{
$\overline{7}$ In his unpublished manuscript 'Non-Actable Desires.' In my discussion I focus mostly on points that Friedrich does not take up in his paper and will note when I am relying on Friedrich's discussion. Timothy Schroeder (2004: 17) also discusses the case of a non-actable desire, that of a committee member who wants the committee to decide in his favor without his doing anything to influence their decision. Again, my discussion differs from Schroeder's own on most points, and where it does not, I make a note of this.
} 
simply not what he desires. In short, Harry has a non-actable desire: he desires that Paula falls in love with him without his engaging in any intentional effort designed to make her fall in love with him. Given the content of this desire, it would be selfdefeating, and therefore irrational, for Harry to be motivated to act on his desire. For he would have to aim at the satisfaction of a desire that cannot - logically cannot be satisfied in this way; he would have to believe that there is some action that promotes what he non-actably desires, i.e., that he can act so as to make Paula fall in love with him without his doing anything to this effect - and this is highly irrational, if not absurd. Consequently, on pain of irrationality, Harry would not be motivated to act on his non-actable desire for the love of Paula.

Dancy is aware that there can be counterexamples to premise (6), although the cases he considers are different from the one above (they concern desires for the uninfluencable such as changing the past). Still, this does not rule out that his responses might be relevant for us; in any case, it is just fair to see how his responses fare with Harry's non-actable desire. His first idea is that though the agent has no motivation to do the action desired, he might still have motivation to do the action that he believes conduces to the desired result. Thus, for instance, it is true that I have no motivation now to die peacefully in my bed although I desire to do so, I do now have motivation to do what conduces to that desired result (Dancy 2000: 88). However, this suggestion takes us nowhere in accommodating Harry's desire. For that example is so constructed that there is no action that would be instrumentally related to the desire. Hence, this response is a non-starter for us. ${ }^{8}$

One might claim, though, that I overlooked an obvious possibility here. If the content of Harry's desire is that Paula falls in love with him without his intentional effort to bring this about, then staying away from Paula is a way of fulfilling his desire without being irrational. I don't think so. If staying away from Paula is taken to be a positive action (if it is a mere refraining, i.e., a negative action, then it will be covered later), there are two ways to understand it. Either Harry believes that staying away from Paula is a means to make Paula fall in love with him, in which case this is not a way of fulfilling his desire. Or Harry believes that staying away from Paula is not a means of making her fall love with him, in which case, once again, this is not a way of fulfilling his desire. Either way, staying away from Paula takes Harry nowhere near to fulfilling his desire - and this is exactly the point of the example: there is no way of satisfying it without exhibiting manifest irrationality.

Dancy introduces his second response through the idea that the following biconditional is true of desires that we cannot satisfy: 'A is motivated to $\varphi$ iff, were an opportunity of $\varphi$-ing per impossibile to arise, A would seize it, in the absence of contrary motivation' (Ibid). He claims that the clause 'per impossibile' is not a mere device because often when we have such desires we also feel frustration exactly because we cannot satisfy them. And this sense of frustration shows that there is

\footnotetext{
${ }^{8}$ What about non-instrumentally related actions? For instance, Harry might be motivated to search for signs of Paula's love, to watch her in secret, and so on. One might use Al Mele's (2003: 23-5) distinction between a desire's providing motivation and encompassing it to support this idea. Harry's non-actable desire for Paula's love would then contribute to the motivational strength of his desire, e.g., to watch Paula secretly and thereby provide, albeit not encompass motivation to act. However, although one might argue that providing motivation is just encompassing motivation to act indirectly, it is an open question if this would be enough to support premise (6).
} 
motivation here, namely motivation that was frustrated because it could not find any outlet (Ibid). To make this response work, we would have to assume the truth of two auxiliary theses: that whenever there is a feeling of frustration, there is also a flicker of motivation, and that it is impossible to have these desires without at least a corresponding feeling of frustration. However, we can certainly question this second claim. ${ }^{9}$ In Harry's case, for instance, this is intuitively not so, probably because the impossibility in question is self-imposed. Harry could do things to make Paula fall in love with him, but he does not want to. He might of course feel frustrated even about such a self-imposed constraint, but he need not do so-and this is enough to refute Dancy's response.

Dancy only proposes these two strategies of accommodating counterexamples to premise (6), but there could be other ways to respond on his behalf. The third response relates to Dancy's second point above. Start with the following claim: the motivation is already there in these cases; it is the motivation to $\varphi$ under the right conditions. To avoid the objection above, we could then propose a broad understanding of 'right conditions.' These conditions concern three things: changes in the world, changes in agency, and changes in the agent. Dancy's strategy above was to focus on the first condition, assuming that the agent does not hold beliefs in what is in fact impossible. This forced him to rely exclusively on frustration, as the only sign of the allegedly present motivation. However, we can give up Dancy's reluctance and make more use of the third condition. In particular, even if there is no - and there will never be any - opportunity to test the presence of motivation, we can still make the claim that the agent is motivated to act, since he would (try) to act were he come to believe that there is such an opportunity.

However, it is clear that there must be a limit to what changes we allow for in the agent's beliefs, dispositions, and so on, for if we understand right conditions broadly enough, we will be able to postulate some motivation in the case of any agent to do anything. To take Tony Milligan's (2007: 317) example, we could say that Gandhi was motivated to commit mass murder that was just a wee bit different from Jack the Ripper's disposition towards a similar series of actions. In support of this claim we could point out that had Gandhi come to believe that it was desirable to engage in serial murder under certain conditions and also to believe that these conditions obtained, he would have tried to act accordingly. This is absurd.

So the question is whether the sort of changes that are required to accommodate Harry's example are admissible. One could argue that they are, by pointing out that, although admitting these changes would mean admitting irrational beliefs among the conditions, this is not a problem. We are talking about motivation here, not normative matters: why care if the price for Harry's motivation is irrationality? Irrational motivation is still motivation, and this is all that matters. But there are two reasons to care. First, Milligan (Ibid: 318) argues that admissible triggering conditions exclude changes in the beliefs concerning what is a desirable outcome, as well as changes in the beliefs concerning which acts are relevant to bringing a particular

\footnotetext{
${ }^{9}$ The first claim is also problematic. See, e.g., Timothy Schroeder's (2004: 20) interpretation of Galen Strawson's example about the weather-watchers who desire the weather to be one way rather than another without any disposition to do something about this. Such creatures, Schroeder points out, can still have feelings of despair if their desires about the weather are not realized: that their desires are not motivationally potent does not rule this out.
} 
desired outcome about. Both conditions are justified, he claims, because were these changes in the agent's beliefs not excluded, the motivations thus postulated to exist would not be dispositions the agent already has, i.e., as he is now, but what he would have after the relevant changes had taken place. Now, the first condition rules out Gandhi's alleged murderous disposition, whereas the second condition would rule out the presence of a disposition in Harry's case (since Harry does not now believe that there are acts of his that could bring about the desired result).

Second, it could be claimed that anything is possible at the level of irrationality Harry would be were he to have the sort of belief he needs to have in order to be motivated: even that Harry is not motivated, because the desire and the belief do not combine to produce motivation (cf. Schroeder 2004: 17). To this it could be pointed out, though, that rationality plays a role already in the idea that desire involves motivation. This is because desire involves motivation to act only together with a means-end belief and only if it is rationally combined with this belief (cf. Nagel 1970: 34). Although in having the belief, Harry would indeed be irrational, he could still rationally combine this irrational belief with his desire, and this is all that matters in this context. Friedrich, who discusses this problem, points out, however, that Harry's irrationality is not merely epistemic, in having the belief, but also practical, in having motivation to act that is self-defeating. And it is hard to believe that rationality would move one even deeper into irrationality (true, rational irrationality exists, but for pragmatic reasons that need not apply in Harry's case).

What about giving up the belief requirement? After all, this seems to cause all our troubles. Indeed, some have argued that motivation — and intentional action based on this motivation - does not need the presence of a suitable means-end belief. Michael Smith (2004: 101-4) opts for a less radical version of this claim: that at least the belief 'I can do A' should be present for motivation to occur. However, Smith's 'I can do A' in Harry's case is the same as his irrational means-end belief: that he can make Paula fall in love with him without his doing anything to this effect. So we are back to where we started. Then, perhaps, we should go one step further. Thus, Al Mele (1988: 726-730) argues that in cases of what he calls intrinsically motivated actions, desire does not need the help of a means-end belief for motivation. For desire, Mele argues, itself has a representational element. It is an action plan, or an element of an action plan, for achieving some pertinent goal or sub-goal and perhaps, but not necessarily, of the steps leading to achieving this goal or sub-goal. But, again, it is hard to see what would be the corresponding representational element of Harry's non-actable desire.

Then, perhaps, we should change the kind of action Harry has motivation for. After all, Harry is presumably motivated to refrain from engaging himself in actions that would be designed to make Paula fall in love with him. For example, Harry is motivated not to show any overt love for Paula and acts accordingly (he does not buy any flowers, does not give her any chocolate, etc.) However, even if we accept this as an account of Harry's desire, it is not more plausible than the one I propose, i.e., it has no explanatory advantage; at the same time its costs are higher. It not only requires us to affirm that negative actions (refrainings) are also actions, but also that negative causation is defensible (since Harry's desire would be the cause of the absence of an event). However, both are contested, hence costly, positions (Bach 2010: 52, 54). It is, moreover, not clear that the alternative account is indeed a good 
one. There is reason to assume that refraining presupposes motivation in the agent to do what he refrains from doing. And even if this is not always so, it does appear plausible in Harry's case, given his strong attraction to Paula (cf. Ibid: 53). However, as the alternative explanation also accepts, Harry has no such positive motivation.

So far, we have tried to save premise (6) by attempting to accommodate Harry's desire. But, perhaps, this is not the way to go: the last two responses I consider take a different route. Dancy might say that Harry's desire is such that it will never give rise to intentional action; hence, it is of no interest for a theory of motivation. While this is a claim a supporter of HTM can make (as Smith 1994: 209 note 7, indeed does), such a blunt discarding of the challenge of Harry's desire is not available to Dancy. For he is arguing for PC and his argument crucially depends on a particular theory of desire, one that equates desire with motivatedness. This is a claim that has a strong modal status, that of necessity; consequently, there can be no counterexamples to it. Thus, even if Harry's desire is impotent when it comes to generating intentional action, it is still a desire and as such is intended to be covered by premise (6) of the argument for PC.

A follow-up on this response might go along the following lines. Dancy's claim is not about desires in general but desires to act: he is focusing on desires to do things not desires that things are so and so. To use Al Mele's (2003: 26) distinction, Dancy is only interested in action-desires, not in state-desires, which might indeed exist without correspoding motivation in the agent. First of all, as it stands, this claim is false: the counterexamples Dancy considers are all state-desires, not action-desires. Of course, he could still be wrong about this choice (not having e.g. recognized the importance of the distinction between the two kinds of desires). However, it is hard to see how he could restrict the scope of premise (6) to action-desires: a rationale for such a move would certainly be wanted in order to avoid the charge of merely begging the question. Besides, restricting the scope of his claim would be selfdefeating. After all, many, if not most, state-desires encompass motivation to act. Hence if Dancy - or for that matter, HTM - leaves them out, a large part of human action will not be covered by their respective theories. This is certainly contrary to their inspirations, which is to give a comprehensive - in fact, constitutive - account of human motivation and action (cf. Smith 2003; Dancy 2003).

Hence, I conclude, unless Dancy shows that Harry's desire is not a desire, his case for premise (6) is lost. How would this go? There are, I think, two plausible candidates for an alternative interpretation of what kind of conative state Harry has: hopes and wishes. The former poses the easier challenge. ${ }^{10}$ Hopes, unlike desires, require uncertainty (combined, maybe, with joy in case the hoped for event occurs); desires do not (cf. Nadler 2008; Schueler 1991: 279). However, in our case, Harry can be confident, in fact, certain, that Paula will fall in love with him, without his intervention - in fact, perhaps this is why he does not want to intervene - he just wants things to run their natural course, so to speak - and still long for Paula's love. Hence, what Harry has is a desire, and not a hope.

\footnotetext{
${ }^{10}$ Note, though, that if hopes and wishes entail desires, this response turns out to be a non-starter. Although I am not able at this point to argue for this claim, it does, intuitively, appear to me to be a plausible suggestion.
} 
Turn now to wishes. Elaborating on ideas by David Velleman (2000: 116-7) and Al Mele (2003: 135-6), we can point to the following difference between desires and wishes: the former requires that the object of the desire is possible to attain, although not necessarily by the agent; the latter does not require this. It is clear that the object of Harry's desire is such that he, Harry cannot attain it (this is logically impossible); yet, it is something that is possible to attain: it is a possible future outcome. Hence, what Harry has is a desire, and not a wish. To the first claim, that Harry's conative state is a desire, the following point needs to be added. Velleman claims that in order to have sufficient conditions on what counts as a desire, we have to add, perhaps, behavioral manifestations. But this does not seem to be impossible in Harry's case: these manifestations can be of all sorts (Sobel and Copp 2002: 261; Mele 2003: 27; Schroeder 2004: 18). Thus, Harry could be disposed to sigh with relief when his desire is satisfied, to admit that he has this desire when he is asked about it, and to think (muse, daydream) about Paula, or, perhaps, even to think about how Paula's love could be achieved. In short, it would be begging the question at this point to hold that the relevant manifestations must include action-dispositions.

It might seem, though, that mere reference to Velleman's idea is not enough to refute PC at this point. For it can be said that Velleman's is just one account of desire, and there are several other competing views. Two points in response. First, I myself am not aware of other views on the difference between wishes and desires. Of course, one could just say that there can be an account of the distinction that helps Dancy out. But this would surely be a very weak claim to make in response to a charge that uses a substantial, existing view of the distinction for support. Second, and more importantly, a brief look at the main theories of desire suggests that Harry's conative state would (or, at least, could) qualify as a desire. ${ }^{11}$

To begin with, a phenomenological account of desire can accommodate Harry's conative state, insofar as there is no reason to rule out that this state has phenomenological content. In other words, there is no reason to hold that Harry's conative state does not feel in any particular way. Next, the pleasure-based theory of desire also appears to be accommodating since, again, there is no reason to rule out that Harry's desire is not a pleasant thought: that Harry is not disposed to take pleasure in the thought that Paula falls in love with him without his intentional efforts to this effect. The good-based theory of desire leads to a similar conclusion. Again, we are in our right to suppose that Harry thinks of the object of his desire as good or at least that it appears to him to be good. The same is the case with attention-based theories of desire. It is natural to suppose that Harry's attention is directed insistently to considerations in favor of Paula's falling in love with him without his intentional efforts to this effect because this thought keeps occurring to him in a favorable light.

\footnotetext{
${ }^{11}$ With the exception of the phenomenological account (for which see Platts 1979, 1981; Schueler 1995), here I follow Schroeder (2009), where further references can also be found. What I do not consider in the text is the action-based theory of desire and the functionalist account. The reason for omission is straightforward in both cases. It would be question-begging to assume the truth of the former, since this is exactly what is at stake here. And the functionalist (dispositional) theory, as my earlier remarks indicate, allows for a mental state like Harry's, unless, as a result of another question-begging move, we assume that the correct dispositional theory includes action-dispositions. In fact, it is worth nothing that Velleman put forward his account exactly as a remedy of the shortcomings of Smith's (1994) dispositional theory of desire.
} 
Finally, the most recently proposed reward (or learning-based) theory of desire can also accommodate Harry's desire: it can plausibly be claimed — or at least not be obviously denied - that representations of Paula's falling in love with him without his intentional efforts to this effect drive Harry's reward-based learning. ${ }^{12}$

Let me sum up this last part of my discussion. It is clear that Harry's conative state is not a hope. On the one available account of the difference between desire and wish, it also comes out that Harry's mental state is not a wish. Moreover, considering major theories of desire — while setting aside question-begging candidates - Harry's conative state would qualify as a desire without any stretch of imagination. Hence, I conclude that Harry's mental state is neither a hope nor a wish, but instead a desire: PC's troubles are not over.

\section{Beyond Pure Cognitivism}

The previous section has shown that neither premise (6) nor the inference to subconclusion (7) of Dancy's argument for PC is defensible. It is not true that desire always comes with motivation in the agent (premise 6) but even if this were the case, it would still not follow that desire is the motivatedness (sub-conclusion 7). Dancy's argument for PC, I conclude, is a failure.

Yet, we may not have to abandon hope of a cognitivist theory of motivation, if we could find an account that does not build on the two disputed claims and/or suffers from problems that beset other cognitivist theories. There are several contenders for this role, and it cannot be my aim in this last section to survey them all. I will do something else. Some of what Dancy says about moral metaphysics and epistemology suggests an alternative theory, and my aim will be to work out this account in some detail. Let me emphasize: even setting aside, as I did in this article, Dancy's rejection of psychologism and taking only the 'psychologist' Dancy as our addressee, I am not claiming that Dancy is forced to endorse this position, or even that he would want to endorse it. My point is that among the available alternative approaches, this is the one that stems from what Dancy himself says, is in line with several of his commitments in other areas, and answers some of the objections that he would have to the theory I propose. In short, that it is what I call a 'Dancyesque' theory of motivation.

Since the upcoming discussion will be somewhat complex, it is worthwhile to sketch the dialectic of my argumentation in advance. I begin with Dancy's distinction between salience and shape and use Margaret Little's account of virtuous perception to cash out these notions in more detail. However, Little leaves us with several unanswered questions, in particular, concerning the substance of the difference between virtuous and non-virtuous cognition. In an effort to fill in the gaps, I introduce Sabine Döring's perceptual theory of emotion. I show how her account of emotions can be used to substantiate Little's account of virtuous perception. In this

\footnotetext{
$\overline{12}$ Of course, it is a possibility that in all these cases one holds that motivation is necessarily involved, i.e., that it is intimately tied to pleasure, affect, reward-based learning, or evaluative thoughts. However, such a move would be unwarranted without further argument. Note, in fact, that some of these theories, such as the reward-based account, are explicitly constructed against the rejection of the idea that desire necessarily involves motivation.
} 
way I piece together a cognitivist account of motivation from ingredients that were originally intended to be independent of each other. I finally show that this theory is Dancyesque in three senses: it stems from Dancy's own account of moral recognition, it is compatible with his moral metaphysics, and it is immune to his criticisms of other theories of motivation.

Let us then turn to the details of my argument. The story starts with a response that Dancy gave to a challenge posed by Caj Strandberg (1999: 179-180). In his answer, Dancy (1999: 219-220) introduces the notions of salience and shape. He describes moral recognition as a two-step procedure (cf. Dancy 1999: 112; 2004: 16: 145). First, the agent recognizes those features of the situation that are salient: they are not merely relevant to what she should do, but stick out, obtrude, or catch the eye among the relevant features. That is, she recognizes what reasons there are for her to act. Second, the agent also notices the way these salient features of the situation relate to each other: she discerns the shape they make up. That is, she realizes what she has overall reason to do. Put in moral language, there is, first, the agent's recognition of the lower order properties, i.e., the salient features of the situation. This is then, second, followed by the agent's discerning the shape these lower order properties combine to form, i.e., realizing that they make the action right.

Now comes the twist. The idea is to make use of these notions to build up an alternative theory of motivation. Here I first rely on work by Margaret Little. She interprets the notions of salience and shape by making use of an analogy from sensory perception. We are familiar with the phenomenon that a picture can be organized under different gestalts, and that gestalt changes make for differences in our experience of the picture: once we see a rabbit there, another time we depict a bird. Moreover, such changes can bring with them differences in propositional knowledge: for instance, we can suddenly come to see the dots as Marilyn Monroe's visage in the pointillist painting. What happens here is exactly what Dancy says above: the agent picks out the salient features and then depicts the overall shape they combine to form (Little 1997: 73). But when the opposite process takes place, when we suddenly lose our 'grip' on the picture, we need not also lose the propositional knowledge we have previously acquired. That knowledge can survive shifts or losses in experimental gestalts: we can still retain our belief that the dots could be seen as the face of Marilyn Monroe, even though we can no longer see it as her visage (Ibid: 74). Hence, seeing and believing are not the same, and the difference between the two cannot be spelled out in propositional terms.

The suggestion is that the same happens in the moral case. The virtuous person's cognition of the situation is like depicting Monroe's face in the picture: every element of the picture suddenly drops into line and the agent sees the action as virtuous, which is not the same as believing that it is virtuous. Discerning a feature as salient and then discerning the shape these salient features form are two stages of this process (Ibid). Talk of moral perceiving or conceiving is thus not accidental. Its aim is to highlight the fact that correctly perceiving that some act is right is not the same as believing that it is right. We already know that this difference is not propositional. Now we learn, Little claims, that the difference is, in part, motivational: there is a necessary connection between virtuous cognition and motivation, but not between moral belief and motivation. This is because virtuous cognition is not merely a cognition, but is also a form of irreducibly practical, i.e., inherently motivating experience (Ibid: 74-5). 
To put it in perhaps more familiar terms, virtuous cognition is inseparable from desire: they either form a unitary mental state or the cognition entails the presence of a desire (Ibid: 70-1).

Naturally, as Little admits, to turn this idea into a full-blown theory, one has to fill in the details. In particular, one has to cash out the difference between virtuous and non-virtuous cognition, which also explains the motivational difference between the two. Unfortunately, Little does not say much about how such an explanation would go. Her - John McDowell inspired - idea is that the virtuous agent's cognition in a particular situation is 'part and parcel of the broad, uncodifiable, practical conception of how to live,' while the nonvirtuous person does not subsume her cognition in this way (Ibid: 75). But then the question becomes what this 'conception of how to live' consists in. The only clue we get from Little, again following McDowell, is that '[i]t is a skill in judging which situations fall under various rich moral classifications such as kind, cruel, obligatory, evil; and what it takes to count as having such a skill, it is claimed, cannot be understood independently of one's having a practical orientation to be identified, if you like, with its judgments' (Ibid: 74-5).

This is not much. Let me sum up what we know. From what has been said previously, we know that the difference between virtuous and non-virtuous cognition cannot be spelled out in propositional terms, that virtuous cognition, unlike nonvirtuous cognition is necessarily motivating, that virtuous cognition is helpfully modeled in analogy with perceptual gestalts, and that it is consistent with the agent's also possessing (retaining) propositional belief (knowledge). And we have just learned that the cognition we are dealing with has to do with a skill, the judgments of which are such that the agent practically identifies with them (which, I take it, is just another way of saying that these judgments are necessarily motivating).

What can we do with these ingredients? Here is a recipe: a (partial) way of filling in the details of the theory that uses these ingredients. The core idea is that the skill mentioned above can (in part) be cashed out in terms of emotions: they are what (partially) provide us with the relevant skill and thereby (partially) constitute the broad conception of how to live that Little is talking about. To make this idea work, we need to have a suitable theory of emotion at hand. This is where Sabine Döring's perceptual theory of emotion enters the picture. ${ }^{13}$

According to Döring (2003: 220), 'an emotion is an occurrent conscious state, with a certain affect, and with a certain kind of intentional content.' For us, the latter two characteristic are important. The intentional content of an emotion is representational: it is subject to correctness conditions. One's fear represents the object of one's fear as being in fact dangerous: one's fear puts forward its content as correct (Ibid: 222). This content is, moreover, perceptual: emotional cognition resembles sense perception in three respects. One, just as there are perceptual illusions, there are also emotional illusions: emotional cognitions are appearances of the truth. 'In fearing a snake that you suddenly encounter on a woodland path it seems to you that the snake is dangerous, and yet you may be sceptical whether the putative snake is in fact a harmless slow worm,' says Döring (2007: 378). Two,

\footnotetext{
${ }^{13}$ For similar work on emotions, motivations, and cognition see Roeser $(2006,2010)$ and Zagzebski $(2003$, 2004). The arguments in Little (1995) suggest that she would have no problem with this direction of thinking.
} 
emotions can persist against and need not be revised in light of one's better judgment. One may judge - in fact, know - the snake in the above example to be not dangerous and still have the persistent impression (appearance) that it is dangerous (this is analogous to well-known perceptual illusions such as the Müller-Lyer illusion). This possibility of conflict without contradiction - i.e., that the content of the perception conflicts with content of the belief without contradicting it - shows that the content of emotions is not inferentially related to the content of other mental states (Ibid: 380). Three, emotional cognitions, just like sense perceptions, but unlike beliefs, have a particular phenomenology that is inseparable from the cognition: the representational content of an emotion cannot be separated from what it is like to experience, i.e., feel the emotion (Döring 2003: 226). One can judge that the gorilla in front of one is dangerous without having the requisite emotion of fear; and one can see the gorilla as dangerous and relate to this affectively: this is when one has the emotion of fear (Döring 2007: 373). At the same time, emotional cognition also differs from sensory perception because of the nature of the phenomenology involved, which is feeling or affect: emotions are affective perceptions (Ibid: 376). Finally, the perceptual content of emotions can be gestalt-like (Ibid: 383 note 17). When, for example, one is amused by another's irritating behavior, the content of this amusement is gestalt-like: one picks out the salient features that make the behavior amusing (that it is over the top irritating) and suddenly sees that the behavior is amusing.

With the help of this theory, we can now turn the ingredients Little has provided us with into an account of motivation. Insofar as the perceptual theory of emotion is defensible, we will have a more detailed account of motivation at hand than what Little has left us with.

Emotions, according to Döring, are affective perceptions. The content of such perceptions, we saw above, can be gestalt-like. More importantly, affective perceptions differ from beliefs, and this difference cannot be spelled out in propositional terms: these perceptions possess a certain phenomenology that beliefs do not have. Affective perceptions, moreover, are less than beliefs: they are appearances of the truth. Although this means that emotions may not get things right, they do nevertheless purport to be representations of the truth. As such, they provide a way of coming to believe (and, possibly, to know) moral propositions (Döring 2003: 227-9). In particular, when the representation is endorsed by the agent, when she takes the appearance at face value, affective perception becomes belief and, possibly, knowledge (Döring 2007: 383). This, as far as I can see, does not rule out that the beliefs acquired via the emotions can be retained even after the emotions are lost. There are two roles emotions can play in acquiring moral beliefs (Döring 2003: 230). If they play a facilitative role, the agent could acquire the belief without the emotion, although having the emotion makes this easier; if they play a constitutive role, the emotion is essential to acquire the belief. In either case, it does not seem to be problematic to hold that once acquired, the agent can retain the requisite belief, even after the emotion is lost.

Turning to the motivational side, affective perceptions are necessarily motivating. It is an open question what exactly plays the active, 'pushing' role, whether it is desire or, as Döring (2010: 195) claims, it is the feeling or affect that accompanies the emotion. We need not decide this here, since what matters for us is just that this is a 
cognitivist theory of motivation - and it is, since the desire/affect is inseparable from the relevant cognition (if the cognition concerned was a belief, and the motivating 'push' would come from a desire, we would have a literal rejection of IC). Finally, to repeat, emotions understood in this way provide the virtuous agent, who has the right kind of emotional make-up, with just the kind of skill that is needed. Virtuous agents, on this understanding, would be people who have emotions that reliably issue in correct moral judgments in different morally challenging situations and who are moved by these emotions to act on those judgments. ${ }^{14}$

With this we have come to the final part of the article. Earlier I said that this account is 'Dancyesque.' One reason for this claim we already saw: the proposed theory stems from certain remarks of Dancy on the process of moral recognition. Having presented the theory, we come to the second and third reason: that the theory is in line with Dancy's commitments in moral metaphysics and that certain objections Dancy would have against the proposal can be dealt with. I proceed in order.

Dancy's (1993: Chap. 5; 2004: 85-6) account of moral properties builds on his notion of resultance. It is the lower order properties, the resultance base, that make an action right (wrong, virtuous, non-virtuous), whereas rightness (wrongness, etc.) itself is the higher order property that exists in virtue of these properties. This notion is contrasted with the more often used notion of supervenience and plays a crucial role in supporting Dancy's (2004: 86-93) particularism. Moral properties, furthermore, are identical with the shape lower order properties, i.e., the relevant saliences combine to form (Dancy 1993: 115). At the same time, moral properties are not identical with the resultance base; Dancy pictures the resultance relation as one of constitution as opposed to identity (Ibid: 116). This, he says, is because there are many ways an action can get to be wrong; in other words, moral properties are multiply realizable (Dancy 2004: 86). Finally, moral properties he understands as identical with the disposition to elicit a merited response, in this case, an intrinsically motivating moral judgment (i.e., a judgment that motivates in its own right, without the help of any other state) (Dancy 1993: 157-163).

None of these elements of Dancy's metaphysics is in conflict with the theory suggested. Resultance, along with the already (re-)interpreted notions of salience and shape, can just as well be accommodated in the new framework as in Dancy's original. As for salience and shape, we have the notion of affective perception, the content of which can be gestalt-like (just as in Little's original story), to do the accommodation for us. Resultance, being a purely metaphysical notion, seems to be compatible with the account of affective perception given here (just as supervenience would be, for that matter). The aspect of multiple realizability Dancy appeals to in support of constitution can also find a foothold in the new system. Recall the analogy with perceptual gestalts. There is more than one way to realize Monroe's face in the picture, i.e., more than one way the dots can add up to form Monroe's face. It is also possible that the same dots are seen to form something else than Monroe's face. Finally, the dispositional view of moral properties fits the new picture too. Its role, chiefly, is to account for the fact that moral properties are intrinsically related to the will': they are such that whenever the agent with a certain competence encounters

\footnotetext{
${ }^{14}$ This requires that we have an account of when one is entitled in endorsing the representational content of one's emotions. For more on this, see Döring (2004).
} 
them, they elicit in this agent an intrinsically motivating response. By substituting moral belief with a special kind of cognition that is inseparable from motivation (i.e., emotion understood as affective perception), the merited response (i.e., the emotion) will be intrinsically motivating also on the proposed theory; in fact, on this reading, a strictly necessary connection between cognition and motivation is established, insofar as emotions necessarily motivate. Furthermore, in case emotions are constitutive of acquiring moral knowledge, virtuous agents cannot come to make certain moral judgments (and gain the requisite moral knowledge), other than by endorsing the content of their emotions. If this is so, the view that moral properties are identical with the disposition to elicit the relevant emotions ('merited response') becomes even more plausible (cf. Döring 2003: 230).

What objection could Dancy have to this account? Since he has no published views on emotions, here I will survey objections he would make against views that reject IC. These theories are relevantly similar in that they also posit a necessary connection between cognition (belief) and motivation (desire). The 'classic' objection, which Dancy also echoes, is that moral judgment and motivation can come apart; our moral phenomenology provides ample proof of this: cases of listlessness caused by depression, fear, illness, physical tiredness, and the like often break the connection between moral judgment and motivation (Dancy 1993: 12; cf. Smith 1994, 123-5). Now, the objection assumes that moral judgment is the same as moral belief, and moral belief does indeed come apart from motivation. However, the proposed view introduces a cognition distinct from belief, namely, affective perception, and claims that this perception does not come apart from motivation. The objection has nothing to say about this connection. ${ }^{15}$ It is true that, upon the agent's endorsement, this perception becomes a belief. Yet, as noted, it is possible that the agent loses the emotion (the above-mentioned factors could well be the causes behind this loss) while retaining the belief. Finally, not all moral beliefs are acquired via emotions, and these beliefs, as far as the proposed theory is concerned, can come apart from motivation.

The next objection Dancy (1993: 21; 2000: 82-4, 93-4) has against views that posit a necessary connection between belief and desire is that they are unacceptably hybrid. There are two ways to make this objection. One concerns scope: Little's own treatment is confined to thick virtue and vice concepts, not even thin moral concepts are involved in her analysis. But what is the problem with a cognitivist theory of motivation that does not claim to be comprehensive? It seems possible, at least not $a$ priori objectionable, to hold that certain actions are explained in one way and others in another way. Moreover, it is unclear why an extension to thin moral concepts and, further, to more general practical concepts would be impossible. Emotions certainly take us beyond thick virtue and vice concepts, in fact, beyond the sphere of morality. And emotions need not exhaust the 'broad conception of how to live' to which Little

\footnotetext{
${ }^{15}$ What if it is not the case that emotions (i.e., affective perceptions) necessarily motivate? Some hold this view, cf. Döring (2010: 192). Then I think the best explanation would be the one Dancy (1993: 24-6) also makes use of: that emotions intrinsically, but not necessarily motivate, and when they don't, this is because of the factors mentioned above. There is still the question of psychopaths, though, that is, of amoral or outright wicked people. There is a huge literature on this, but the 'emotional theorist' would probably say that these people simply don't possess the relevant moral emotions.
} 
has appealed. Further elements might be introduced, thereby widening the scope of the proposed theory.

The other reading of the charge is that singling out certain beliefs as motivating forces us to explain why these beliefs can motivate, but others cannot. However, we are dealing with not a particular kind of belief, but with a particular cognition, namely affective perception. This perception is a distinct cognition, in part because it is motivating. To deny this would amount to denying that emotions can motivate. This view, I submit, is absurd. And the beliefs that one acquires upon endorsement of the content of these perceptions do not need to motivate, as noted above. If they do, this is because of the persisting emotion that backs the belief. Hence, again, there is nothing mysterious here.

The third objection derives from some remarks of Dancy (2004: 142-3) on the practical epistemology he favors. Although he holds that the knowledge we bring to a new case is informed by our past experience and is an instance of knowledge-how, he thinks differently about what we do in those situations. He explicitly claims that the two abilities used on these occasions, the skill of discerning the salient features of the situation and the skill of discerning the overall shape of these features, both give rise to propositional knowledge. However, the perceptual theory of emotion used here does not deny that, via emotions, we gain propositional knowledge. Far from it. If the agent endorses the representational (perceptual) content of his emotion, he comes to believe, and possibly, to know this content. All this goes along propositional lines, hence in no contradiction to what Dancy says.

As a related point, which gives us our fourth and final objection, Dancy (2004: 143-6) claims that the abilities involved in discerning salience and shape are not sensory. I agree with Dancy that these abilities are not sensory, since this would mean that they either assume the existence of a special sense organ or a form of regular sense perception, and I find both assumptions implausible (cf. Dancy 2010). However, the perceptions emotions involve are not sensory: they are affective. They share certain features with sensory perception, but they also differ from them. In particular, their phenomenology is different - that of feeling or affect — and they do not require any kind of sense organ to be effective. Thus, again, there is no contradiction to what Dancy says.

\section{Summary and Concluding Remarks}

In this article I have done two things. First, after having presented, against the background of the Humean Theory of Motivation, Dancy's Pure Cognitivism, I have shown why Dancy's argument for this theory is a failure. Second, based in part on what Dancy says, I have presented the basics of an alternative cognitivist theory of motivation. Naturally, it is not my intention to claim that my discussion of this alternative gives us answers to all our questions and put all our doubts to rest. There is a long way to go in this or any other suitable direction before we can confidently claim to have provided a full-blown theory of motivation. However, if the above discussion has shown one thing - that there is life, cognitivist and 'Dancyesque', beyond pure cognitivism - then we have done what we could in this article. 
Acknowledgments This article has been long in the making. Over the years I have accumulated much debt to many audiences and colleagues across Europe, so many, in fact, that it would be hardly possible to name them all here. Therefore, in this way, I would like to thank all of them for their help with the article. Finally, I would like to thank Daniel Friedrich for giving me permission to use his unpublished work in the article and also an anonymous referee for Acta Analytica who made me rethink (and rewrite) important parts of the article. My research on the subject has been funded by a project grant from the German Research Foundation (grant no. TA 820/1-1) and earlier by a grant from the Swedish Research Council (grant no. 435-2007-7830).

\section{References}

Bach, K. (2010). Refraining, omitting, and negative acts. In T. O’Connor \& C. Sandis (Eds.), A companion to the philosophy of action (pp. 50-57). London: Wiley-Blackwell.

Bond, E. J. (1983). Reason and value. Cambridge: Cambridge University Press.

Cuneo, T. (2002). Reconciling realism with humeanism. Australasian Journal of Philosophy, 80(4), 465486.

Dancy, J. (1993). Moral reasons. Oxford: Blackwell.

Dancy, J. (1999). Motivation, dispositions and aims. Theoria, 99(2-3), 212-224.

Dancy, J. (2000). Practical reality. Oxford: Oxford University Press.

Dancy, J. (2003). Replies. Philosophy and Phenomenological Research, 67(2), 468-490.

Dancy, J. (2004). Ethics without principles. Oxford: Oxford University Press.

Dancy, J. (2005). Two ways of explaining action. In J. Hyman \& H. Steward (Eds.), Agency and action (pp. 25-42). Cambridge: Cambridge University Press.

Dancy, J. (2006). Acting in the light of appearances. In C. and G. MacDonald (Ed.), McDowell and his critics (pp. 121-132). Oxford: Blackwell.

Dancy, J. (2010). Moral perception. Proceedings of the Aristotelian Society Supplementary, 84, 99-117.

Darwall, S. (1992). Internalism and agency. Philosophical Perspectives, 6, 155-174.

Davidson, D. (1963). Actions, reasons, and causes. Reprinted in his essays on actions and events (pp. 321). Oxford: Oxford University Press.

Döring, S. (2003). Explaining action by emotion. The Philosophical Quarterly, 53(211), 214-230.

Döring, S. (2004). Gründe und Gefühle. Zur Lösung 'des' Problems der Moral, Habilitationsschrift. Universität Duisburg-Essen.

Döring, S. (2007). Seeing what to do: affective perception and rational motivation. Dialectica, 61(3), 363394.

Döring, S. (2010). What a difference emotions make. In T. O’Connor \& C. Sandis (Eds.), A companion to the philosophy of action (pp. 191-199). London: Wiley-Blackwell.

Hubin, D. C. (1996). Hypothetical motivation. Nô̂s, 30(1), 31-54.

Little, M. O. (1995). Seeing and caring: the role of affect in feminist moral epistemology. Hypatia, 10, 117-137.

Little, M. O. (1997). Virtue as knowledge: objections from the philosophy of mind. Nôus, 31(1), 57-79.

Lohmar, A. (2008). The failure of pure cognitivism. Grazer Philosophische Studien, 76, 149-166.

McDowell, J. (1978). Are moral requirements hypothetical imperatives? Proceedings of the Aristotelian Society, Supplementary Volume, 53, 13-29.

McDowell, J. (1979). Virtue and reason. The Monist, 62(3), 331-350.

McNaughton, D. (1988). Moral vision: An introduction to ethics. Oxford: Blackwell.

Mele, A. (1988). Effective reasons and intrinsically motivated actions. Philosophy and Phenomenological Research, 48, 723-731.

Mele, A. (2003). Motivation and agency. New York: Oxford University Press.

Milligan, T. (2007). Whimsical desires. Ratio, 20(3), 308-319.

Nadler, S. (2008). Baruch Spinoza. Stanford Encyclopedia of Philosophy (2008 Winter edition), E. N. Zalta (ed.), <http://plato.stanford.edu/entries/spinoza/>

Nagel, T. (1970). The possibility of altruism. Princeton: Princeton University Press.

Phillips, D. Z. (1977). In search of the moral 'must': Mrs. Foot's fugitive thought. The Philosophical Quarterly, 27(107), 140-157.

Platts, M. (1979). Ways of meaning. London: Routledge.

Platts, M. (1981). Moral reality and the end of desire. In M. Platts (Ed.), Reference, truth, and reality (pp. 69-82). London: Routledge. 
Roeser, S. (2006). A particularist epistemology: 'affectual intuitionism'. Acta Analytica, 21(1), 33-44.

Roeser, S. (2010). Moral emotions and intuitions. Basingstoke: Palgrave Macmillan.

Shaver, R. (2006). Sidgwick on moral motivation. Philosophers' Imprint, 6(1), 1-14.

Schroeder, T. (2004). Three faces of desire. New York: Oxford University Press.

Schroeder, T. (2009). Desire. Stanford Encyclopedia of Philosophy (Winter 2009 Edition), E.N. Zalta (ed.), $<$ http://plato.stanford.edu/archives/win2009/entries/desire/>

Schueler, G. F. (1991). Pro-attitudes and direction of fit. Mind, 100(2), 277-281.

Schueler, G. F. (1995). Desire: its role in practical reason and the explanation of action. A Bradford Book. Cambridge: MIT Press.

Smith, M. (1994). The moral problem. Oxford: Blackwell.

Smith, M. (2001). Some not-much-discussed problems for non-cognitivism in ethics. Ratio, 14, 93-115.

Smith, M. (2003). Humeanism, psychologism, and the normative story. Philosophy and Phenomenological Research, 67(2), 460-467.

Smith, M. (2004). Instrumental desires, instrumental rationality. Proceedings of the Aristotelian Society, Supplementary Volume, 78, 93-109.

Smith, M. (2010). Humeanism about motivation. In T. O'Connor \& C. Sandis (Eds.), A companion to the philosophy of action (pp. 153-158). London: Wiley-Blackwell.

Sobel, D., \& Copp, D. (2002). Desires, motives, and reasons: scanlon's rationalistic moral psychology. Social Theory and Practice, 28(2), 243-276.

Strandberg, C. (1999). Dispositional moral properties and moral motivation. Theoria, 65(2-3), 171-192.

Velleman, J. D. (2000). The guise of the good. In his The possibility of practical reason (pp. 99-122). New York: Oxford University Press.

Zagzebski, L. (2003). Emotion and moral judgment. Philosophy and Phenomenological Research, 66(1), 104-124.

Zagzebski, L. (2004). Divine motivation theory. Cambridge: Cambridge University Press. 